\title{
Characterization of ceramic layers for thermal barriers coatings
}

\author{
I. Mercioniu ${ }^{1}$, A.M. Vlaicu ${ }^{1}$, C. Ghica ${ }^{1}$
}

1 National Institute of Materials Physics, 405A Atomistilor Str., 077125 Magurele-Ilfov, Romania

* Correspondence: imercioniu@infim.ro; Scopus ID: 25825319200

Thermal barrier coatings (TBC) represent the most effective system to protect structural components from damage caused by high temperature and corrosive/erosive environments. Yttria-stabilized zirconia (YSZ) is among the most studied ceramics for such applications. The adherence of the ceramic layer to the metallic object needing thermal protection is one of the critical issues in real operation conditions at high temperature or under thermal shocks. A bond coat is necessary to ensure the adherence of the YSZ top coat to the substrate. In our work, Y, Ta doped NiCrAl compounds bond coat obtained by air plasma spray (APS - Fig. 1) and high velocity air fuel (HVAF) have been subjected to increasing temperature thermal treatments $(700-1300$ $\mathrm{oC} / 5 \mathrm{~h}$ ). The system behavior under thermal stress has been investigated by microstructural methods including XRD, SEM and TEM. The TEM/STEM results (Fig. 2) show the oxidation resistance of the HVAF vs APS deposited bond coats. Spurious Y-Ta-O structures have been evidenced which otherwise failed to be observed by conventional XRD/SEM-EDS (Fig. 3).

The identified microphases which appear at the high temperature represent the nucleation point for the layer of thermally grown oxide (TGO) with a decisive role in the delaminating process at high temperature. We show that in the APS-deposited bond coat the TGO was distributed in the whole mass of the bond coat, while in the HVAF-deposited bond coat the TGO is pushed toward its outer surface.

Formation of TGO is initiated both at the ceramic-bond layer interface and into the pores existing inside the bond layer. The size and morphology of the pores inside the deposited layers depend on the deposition method (ex: APS or HVAF). Fracture occurs at the YSZ/TGO interface. Below fracture, the TGO to bond coat transition is abrupt $(\sim 5-10 \mu \mathrm{m})$. Diffuse $\mathrm{Al}_{2} \mathrm{O}_{3}$ can be observed in TGO/BC region (2), which segregates at the $\mathrm{BC} /$ substrate interface (3); TGO does not built in a compact oxidation barrier layer. Ta, Y, Ti segregations form into the top coat, bond coat and substrate.

Keywords: thermal barrier coatings, Yttria-stabilized zirconia, Y-Ta-O.

\section{Funding}

Not applicable.

\section{Acknowledgments}

PROCEEDINGS INTERNATIONAL | https://conferenceproceedings.international |

Cite This Work: Mercioniu, I.; Vlaicu, A.M.; Ghica, C. Characterization of ceramic layers for thermal barriers coatings. Proceedings Int 2019, 1, 0029-0031. https://doi.org/10.33263/Proceedings 11.00290031 
Not applicable.

\section{Conflicts of Interest}

The authors declare no conflict of interest.

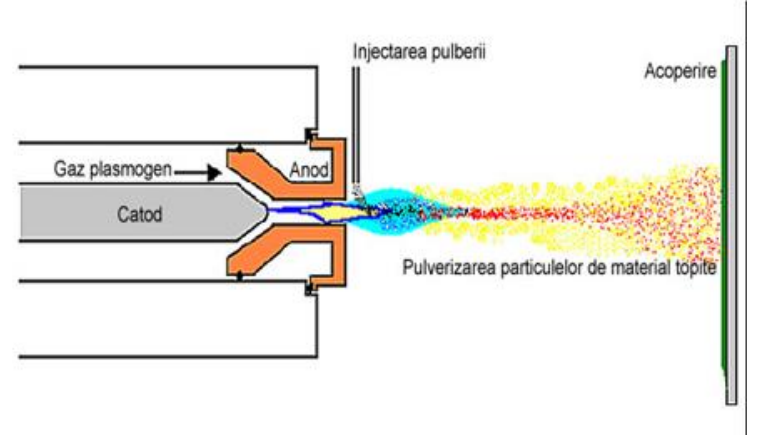

Figure 1. Schematics of the APS deposition process.

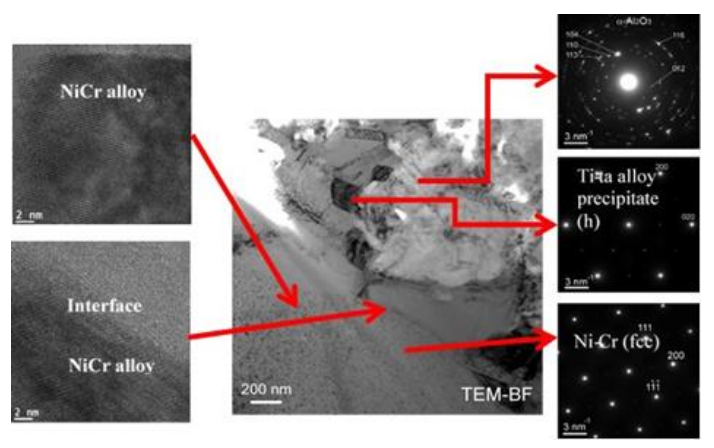

Figure 2. Description of figure 1.

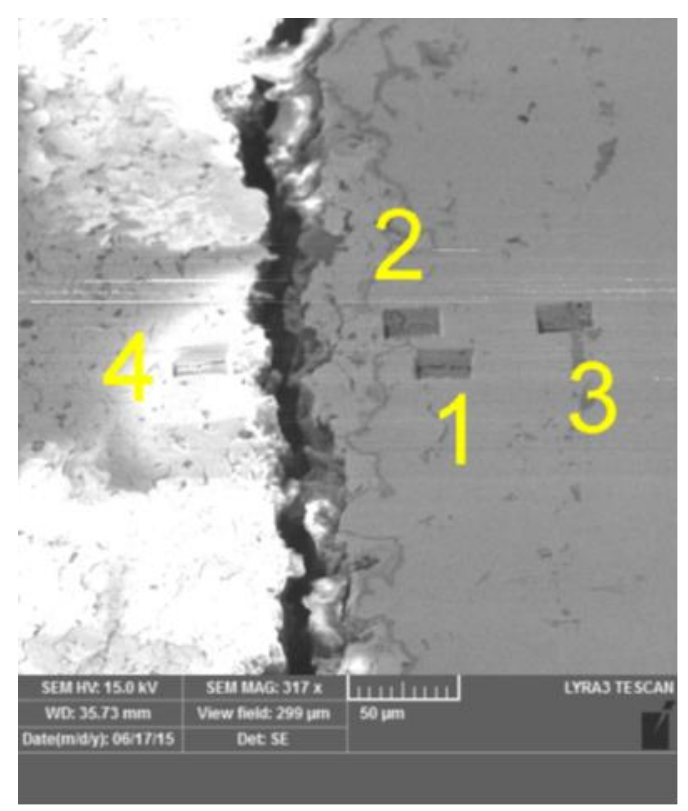

Figure 3. Cross-section SEM image indicating the spots from where thin lamellas have been extracted around the TBC-substrate interface for TEM investigations: 1- bond coat (BC); 2 - TGO/BC; 3 - substrate; 4 - top coat.

\section{References}

1. Urban, K.W. Studying atomic structures by aberration-corrected transmission electron microscopy. Science 2008, 321, 506, https://doi.org/10.1126/science.1152800.
2. Van Aert, S.; Batenburg, K.J.; Rossell, M.D.; Enri, R.; Van Tendeloo, G. Three-dimensional atomic imaging of crystalline nanoparticles. Nature 2011, 470, 374, https://doi.org/10.1038/nature09741. 


\section{Mercioniu, A.M. Vlaicu, C. Ghica}

3. Clark, D.R.; Christensen, R.J.; Tolpygo, V. The evolution of oxidation stresses in zirconia thermal barrier coated superalloy leading to spalling failure. Surface and Coating Technology 1997, 94-95, 89-93, https://doi.org/10.1016/S0257-8972(97)00483-0.

4. Seiler, P.; Baker, M.; Beck, T.; Schweda, M.; Rosier, J. FEM simulation of TBC failure in a model system. Journal of Physics: Conference Series 2010, 240, 012069.

5. Seiler, P.; Baker, M.; Rosler, J. FEM simulation of oxidation induced stresses with a

6. coupled crack propagation in a TBC model system.

Mat. Sci. Eng. 2010, 10, 012056.
7. Limarga, A.M.; Vaben, R.; Clarke, D.R. Stress Distributions in Plasma-Sprayed Thermal Barrier Coatings Under Thermal Cycling in a Temperature Gradient. J. Appl. Mechanics 2011, 78, 011003-1, https://doi.org/10.1115/1.4002209

8. Celko, L.; Ricankova, V.; Klakurkova, L.; Podrabsky, T.; Dvoracek, E.; Svejcar, A. Changes in Microstructure of Air Plasma Sprayed M-CrAlY Coatings After Short Thermal Exposure in Argon Atmosphere Acta Phys. Polonica A 2011, 120, 336.

(C) 2019 by the authors. This article is an open access article distributed under the terms and conditions of the Creative Commons Attribution (CC BY) license (http://creativecommons.org/licenses/by/4.0/). 